\title{
Low vagal tone is associated with impaired post stress recovery of cardiovascular, endocrine, and immune markers
}

\author{
Cora Stefanie Weber · Julian F. Thayer • Miriam Rudat • \\ Petra H. Wirtz • Frank Zimmermann-Viehoff • Alexander Thomas • \\ Frank H. Perschel • Petra C. Arck • Hans C. Deter
}

\begin{abstract}
Reduced heart rate variability (HRV) and delayed blood pressure recovery are associated with increased cardiovascular risk. Besides this evident link, the vagus is thought to play an inhibitory role in the regulation of other allostatic systems, including inflammation and the hypothalamic-pituitary-adrenal (HPA) axis. However, human evidence is scarce. To further explore these associations and with special regard to the postulated mediating
\end{abstract}

Communicated by Susan Ward.

C. S. Weber $(\square) \cdot$ M. Rudat · F. Zimmermann-Viehoff .

A. Thomas · H. C. Deter

Department of Psychosomatic Medicine and Psychotherapy,

Charité Universitätsmedizin, Campus Benjamin Franklin,

Hindenburgdamm 30, 12200 Berlin, Germany

e-mail: cora.weber@charite.de

J. F. Thayer

Department of Psychology, Ohio State University,

Columbus, OH, USA

J. F. Thayer

Mannheim Institute of Public Health, Social and Preventive

Medicine, Mannheim Medical Faculty, Heidelberg University,

Mannheim, Germany

P. H. Wirtz

Clinical Psychology and Psychotherapy,

University of Zurich, Zurich, Switzerland

F. H. Perschel

Central Institute of Laboratory Medicine and Pathobiochemistry,

Charité Universitätsmedizin, Campus Virchow-Klinikum,

Berlin, Germany

P. C. Arck

Laboratory for Psychoneuroimmunological Research,

Charité Universitätsmedizin, Campus Virchow-Klinikum,

Berlin, Germany role of the vagus, we hypothesised that subjects with low vagal tone as indexed by reduced resting HRV would show impaired post-stress recovery of cardiovascular, endocrine and immune system markers involved in cardiovascular pathology. 44 healthy men underwent a standardised mental stress test. Besides continuous measurement of systolic and diastolic blood pressure (SBP, DBP), heart rate (HR), and HRV serum cortisol, tumour necrosis factoralpha (TNF-alpha), and interleukin-6 (IL-6) were measured before, after, 20, and $60 \mathrm{~min}$ after stress. Low versus high HRV groups was defined by median split on resting HRV (RMSSD). The task elicited significant time effects for SBP, DBP, HR, HRV, cortisol, and TNF-alpha. Subjects with low baseline HRV showed almost no modulation of HRV coupled with overall reduced HRV levels, and impaired recovery of DBP, cortisol, and TNF-alpha. Confirming our hypothesis, low vagal tone was associated with impaired recovery of cardiovascular, endocrine, and immune markers in healthy males. The data support an inhibitory role of the vagus in the regulation of allostatic systems as described in the neurovisceral integration model. We posit reduced resting HRV as a risk marker for future cardiovascular and other stress-related disease.

Keywords Heart rate variability - Stress - Recovery · Blood pressure $\cdot$ Cortisol $\cdot$ TNF-alpha

\section{Introduction}

Heart rate variability (HRV) is a non-invasive tool to measure autonomic nervous system activity of the heart by power spectral analysis of the heart rate (HR) time series (Akselrod et al. 1981). Autonomic imbalance implying sympathetic overactivity and parasympathetic underactivity play a 
central role in the development and maintenance of essential hypertension (Brook and Julius 2003). Decreased HRV is associated with increased risk of hypertension (Liao et al. 1996), coronary artery sclerosis (Huikuri et al. 1999), acute cardiac events (Tsuji et al. 1996), death from coronary artery disease (Tsuji et al. 1996) and all-cause mortality (Task Force of the European Society of Cardiology and the North American Society of Pacing and Electrophysiology 1996).

Moreover, decreased vagal activity is thought to be linked to other systems associated with physiological regulation and allostasis such as the hypothalamic-pituitaryadrenal cortex (HPA) axis and inflammation (Thayer and Sternberg 2006). Chronic allostatic load, a term for the burden of chronic stress and accompanying changes in personal behaviours, may lead to disease in the long run mediated via autonomic, neuroendocrine, immune, or central nervous system activity (McEwen 1998). According to the allostatic load model, healthy organisms are able to mount an appropriate response to stressors but return to basal levels after the stressor has ended. Those organisms that show continued stress responses after the stressor is over are at increased risk for poor health outcomes. Thus, besides excess cortisol and pro-inflammatory cytokines, delayed post-stress recovery may be one manifestation and act as a mediating link between stress and cardiovascular disease (Brosschot et al. 2005). For example, delayed recovery of blood pressure and HRV following brief laboratory-induced psychosocial stress predicted 3-year increases in blood pressure (Steptoe and Marmot 2005, 2006).

Cortisol, the key stress hormone of the hypothalamuspituitary-adrenal cortex (HPA) axis, interacts with central, sympathetic, and renal mechanisms and plays a potent role in blood pressure regulation. Literature suggests that persons at risk for the development of hypertension, e.g. borderline hypertensives, salt-sensitive males, and those with a family history of hypertension, show elevated levels of plasma cortisol (al'Absi et al. 1994; al'Absi and Arnett 2000; Walker et al. 1998; Watt et al. 1992; Weber et al. 2008). Furthermore, an inverse relationship between cortisol and HRV was observed in healthy adults (Thayer et al. 2006) which could reflect the inhibitory influence of the prefrontal cortex (PFC) on the amygdala reported in both animal and human studies (Thayer 2006; Thayer and Brosschot 2005). Elevated levels of cortisol, e.g. induced by stress, were postulated to disturb the functional connectivity between the PFC and the amygdala via altered serotonin levels. The inhibitory control that the PFC exerts on the amygdala is thought to be at least partially vagally mediated and thus is consistent with a neurovisceral integration model which stresses the importance of the parasympathetic nervous system in providing negative feedback on sympathoexcitatory stress responses (Thayer and Sternberg 2006; Thayer and Lane 2009).

Besides the autonomic nervous system and the HPA axis, inflammatory processes are involved in the pathogenesis and maintenance of vascular pathology (Ross 1999; Packard and Libby 2008). Elevated blood levels of proinflammatory cytokines such as tumour necrosis factor alpha (TNF-alpha) (Ridker et al. 2000a) and interleukin-6 (IL-6) (Ridker et al. 2000b) are associated with an increased risk of acute cardiovascular events.

Importantly, there is recent evidence that the parasympathetic system inhibits the production of pro-inflammatory cytokines by activated monocytes/macrophages and thus decreases local and systemic inflammation (Marsland et al. 2007; Sloan et al. 2007; Thayer and Fischer 2009), as predicted by the "cholinergic anti-inflammatory pathway" (Tracey 2002). Afferent vagal neurons are thought to relay sensory information regarding early inflammatory activity to the brain, resulting in the activation of efferent vagal fibres leading to the suppression of pro-inflammatory cytokine release. However, whereas there is convergent evidence from animal studies (Bernik et al. 2002; Borovikova et al. 2000; Wang et al. 2003) clinical evidence in humans is just starting to become available, e.g. higher HRV-derived estimates of vagal activity were associated with lower production of TNF-alpha and IL-6 in a mixed sample of healthy adults (Marsland et al. 2007), as well as in women with coronary heart disease both time and frequency domain indices of HRV were negatively correlated with IL-6 levels (Janszky et al. 2004).

To date, no studies have examined the time course of stress responses in cardiovascular, endocrine, and immune responses simultaneously in individuals stratified by risk using resting HRV. Therefore, in the context of the aboveoutlined associations of the autonomic nervous system, HPA axis, and immune system and with special regard to the postulate of a mediating role of the vagus, the present study investigated acute stress and recovery effects of cardiovascular, endocrine, and immune system markers in healthy males. We hypothesised that subjects with low resting vagal tone as indexed by reduced resting HRV would show impaired post-stress recovery of diastolic blood pressure (DBP), cortisol, and the pro-inflammatory cytokines TNF-alpha and IL-6.

\section{Methods}

Study population

Subjects were recruited by advertisement on the university and clinic campus. Recruitment and assessments took place over a period of 10 months (between January and October 
2006). Inclusion criteria were $20-50$ years of age, male, healthy namely absence of hypertension, allergies, asthma, and other acute or chronic conditions, no psychiatric illness or other psychopathology in the past or at present, normal weight (body mass index (BMI) $>18.5$ and $<30 \mathrm{~kg} / \mathrm{m}^{2}$ ), and no regular medication. Subjects were examined by an internist to verify the above inclusion criteria. Further, a complete blood count was performed on each subject on the day of the experiment prior to the stress task to ensure absence of acute or chronic inflammation or any other abnormalities such as a dysbalance in the hydration status.

\section{Procedure}

Subjects were invited individually for psychophysiological testing in the lab at 09:00. They were instructed to go to bed not later than 23:30 the night before, to get up not later than 07:30, to abstain from caffeinated, alcoholic, or any other pharmaceutical substances the night before, and to have a usual light breakfast with no more than two cups of coffee or black tea on the morning of the appointment.

Subjects were seated comfortably in a high-backed chair in a quiet room with an ambient temperature of $20-24^{\circ} \mathrm{C}$. After the first instructions, an 18-G cannula was inserted in a right forearm vein. They then had $30 \mathrm{~min}$ time to fill out standardised psychological questionnaires on perceived stress (Perceived Stress Questionnaire by Levenstein et al. 1993, German version by Fliege et al. 2005), anger (STAXI by Spielberger 1999, German version by Schwenkmezger and Hodapp 1991), and anxiety (STAI by Spielberger 1983, German adaptation by Laux et al. 1981) (data not shown, Weber et al. in preparation) and get accustomed to the environment.

Thereafter, electrodes and transducers for detection of ECG and blood pressure were attached to the chest, nondominant arm, and hand. SBP and DBP were recorded continuously using the Finapres device (Ohmeda 2300, Louisville, CO, USA) attached to the middle digit of the nondominant hand. HR was continuously measured by electrocardiography.

The physiological assessment started with a 5-min resting phase (R1). After R1, an initial blood sample was taken ("before stress"). Thereafter, the stress test began with the manometer test, with a duration of circa $8 \mathrm{~min}$, of which only the first $5 \mathrm{~min}$ were used for the analyses, followed by a 5 -min mental arithmetic task (both detailed below). Immediately after, the second blood sample was taken ("after stress"), followed by a 5-min recovery phase termed resting phase 2 (R2). 20 and 60 min after stress, third and fourth blood samples were taken. In the recovery period, subjects remained seated, completed post-stress questionnaires (not shown, see above), and were allowed to read a light entertaining magazine (comic). Blood samples were centrifuged immediately, aliquoted, and kept frozen at $-80^{\circ} \mathrm{C}$ until assayed. Subjects were informed of the experimental risks and signed an informed consent document prior to the investigation. The study protocol including the process of obtaining informed consent was approved by the local ethics committee.

\section{Mental stress test}

\section{Manometer test}

The manometer test is a well-established standardised computer-based information processing task performed under time pressure (Buchholz et al. 2003; Deter et al. 2001; Weber et al. 2007, 2008; Zimmermann-Viehoff et al. 2008). All tests and instructions were given on a computer monitor. Subjects were presented with an increasing number of three to eleven clocks and had to rapidly decide whether one or more hands of the clocks deviated by more than $90^{\circ}$ from the direction of an arrow shown on the top of the screen. Responses were performed by manipulating a mouse with the dominant arm. Wrong answers were indicated by a loud acoustic signal. During the course of the test, the time allowed for the decision was subsequently shortened by $30 \%$ until the participant made a mistake. After a mistake, the time allowed for the decision was extended by $30 \%$. This algorithm maintained an individually adapted workload.

\section{Mental arithmetic test}

Subjects were then presented via computer with an increasingly difficult series of mental calculations involving addition, subtraction, and division with feedback on their performance (provided by Dr. Immo Curio, Bonn, FRG).

\section{Cardiovascular data analyses}

All cardiovascular signals were continuously recorded at $1,000 \mathrm{~Hz}$ with DOS-Software (Turbolab, Stemmer, Puchheim, FRG). The electrocardiographic and finger blood pressure curves (recorded with the Finapres) were analysed off-line under visual artefact control by ALYS software (version 1.18, T. Sudhop and H. Schaechinger, Basel, Switzerland). The Finapres has shown good accuracy, reproducibility, and validity in a wide range of situations (Imholz et al. 1993). However, it is known to overestimate absolute blood pressure levels. As we are interested in changes over time this is not a concern for the present investigation.

Continuous monitoring of cardiovascular parameters began with R1, followed by manometer test, mental 
arithmetic test, and R2. For each of the 5-min phases, means of SBP, DBP, HR, and HRV were computed to be used for the statistics. Therefore, cardiovascular parameters reflect an integrated value over a complete measurement period.

\section{Heart rate variability}

Power spectral density of HR was analysed by Fourier transformation according to published standards (Akselrod et al. 1981; Task Force of the European Society of Cardiology and the North American Society of Pacing and Electrophysiology 1996). We chose the root mean square of the successive differences (RMSSD, in $\mathrm{ms}$ ) in R-R intervals as an index of vagally mediated HRV. In the present sample, RMSSD was significantly correlated with the high-frequency band $(0.15-0.40 \mathrm{~Hz})$ of the spectral-derived HRV measure $(r=0.90, P<0.0001)$.

Biochemical analyses

\section{Cortisol}

Serum cortisol was measured using a solid-phase ${ }^{125} \mathrm{I}$ radioimmunoassay (Coat-A-Count ${ }^{\circledR}$ Cortisol RIA, DPC Biermann GmbH, Bad Nauheim, Germany) counted in a 1277 Gammamaster Automatic Gamma Counter (Perkin Elmer, Rodgau, Germany). The intraassay coefficient of variation of this RIA was $5.1 \%$ or less in seven trials ( $n=20$, mean concentration $85.5-938 \mathrm{nmol} / \mathrm{L}$ ), and the interassay coefficient of variation was $6.4 \%$ or less in 3 trials ( $n=20$, mean concentration 91.0-993 nmol/L). All samples were measured in duplicate.

\section{TNF-alpha and IL-6}

The cytokines were measured using a high-sensitive solidphase ELISA (High-Sensitive Tumor Necrosis Factor alpha Human Biotrak and High-Sensitive Interleukin 6 Human Biotrak, Amersham Biosciences Europe $\mathrm{GmbH}$, Freiburg, Germany). Optical densities were read on a standard micro-titer plate reader (Dynex MRX, Dynex Technologies, Berlin, Germany). All samples were measured in duplicate. TNF-alpha standards are calibrated to WHO reference lot $87 / 650$, whereas $1 \mathrm{pg}$ of assay standard refers to $3 \mathrm{pg}$ of WHO standard $(\sim 0.12 \mathrm{WHO}$ units). IL-6 standards are calibrated to the NIBSC reference lot $89 / 548$, whereas $1 \mathrm{pg}$ of assay standard refers to 3 pg of NIBSC standard (0.3 NIBSC units). Within-assay precision and between-assay precision were $<10 \%$ in both assays. The detection limit for both assays is denoted by the manufacturer to be $0.1 \mathrm{pg} / \mathrm{ml}$.
Statistical analyses

Data were analysed by the SPSS statistical software package (SPSS Inc., Chicago, Illinois, USA). Complete data sets with all four time points were available for $n=43$ subjects for the cardiovascular data, $n=42$ for cortisol, and $n=33$ for the cytokines. Missing data were due to technical errors.

For the cardiovascular variables a two groups (high versus low resting HRV) by four time periods (R1, manometer, mental arithmetic, R2) ANOVA was performed to determine time, group, and interaction effects (multivariate tests, Roy's Greatest Characteristic Root) (Vasey and Thayer 1987). For the endocrine and immune measures also a two groups (high versus low HRV) by four time points (pre-stress, immediately after stress, 20 and $60 \mathrm{~min}$ after stress) ANOVA was performed. Age was entered as a covariate to check for significant group or interaction effects (time $\times$ age, group $\times$ age). $T$ tests for paired samples were used to check for differences of SBP, DBP, and HR between individual time points (pre-planned). Further, $t$ tests for independent samples or univariate ANOVA were used to check for differences between high versus low HRV groups at individual time points. Pearson correlations (two-tailed) were used to check for associations between variables. Data are presented as mean \pm standard deviation. Effect sizes are reported as point-biserial correlations $\left(r_{\mathrm{pb}}\right)$. Significance was set at $P<0.05$.

\section{Results}

Sample characteristics

The final study sample consisted of 44 Caucasian men with a mean age of $30 \pm 7$ years and a BMI of $23 \pm 3 \mathrm{~kg} / \mathrm{m}^{2}$. $77 \%(n=34)$ were students and $21 \%(n=9)$ academic professionals. Most of them were involved in moderate sports activities (with a mean of $2.5 \pm 1.5 \mathrm{~h}$ of physical exercise per week); none of them smoked, and none of the subjects showed any signs of drug abuse or addiction (as it was part of the inclusion criteria). Further, none of the subjects showed any signs of dehydration, acute or chronic inflammation, other illness or pathological condition. The physical examination by an internist confirmed an intact physical status of all participants.

Two groups were defined based on a median split on resting RMSSD (median $=35.5 \mathrm{~ms}$, high versus low RMSSD). This value is nearly identical to the value that we have found for patients in previous investigations and may be a useful value for risk assessment (Melzig et al. 2009; Kraemer et al. 2001). These groups differed significantly in 
RMSSD as expected (low HRV group: $25.8 \pm 6.5 \mathrm{~ms}$; high HRV group: $51.7 \pm 13.9 \mathrm{~ms}, \quad F[1,41]=64.0$, $\left.P<0.0001, r_{\mathrm{pb}}=0.78\right)$. Groups did not differ with regard to BMI, resting HR, SBP, or DBP (all $P>0.05$ ). However, the high HRV subjects were significantly younger $(27 \pm 5$ vs. $32 \pm 8$ years; $\left.F[1,41]=5.142 ; P=0.029, r_{\mathrm{pb}}=0.33\right)$. Therefore, age was entered as a covariate in all analyses (detailed below).

Cardiovascular effects

\section{Whole sample}

The combined stress task elicited significant cardiovascular responses as indicated by significant time effects for SBP (mm Hg; R1: $134.8 \pm 16.7$; manometer: $146.8 \pm 19.9$; mental arithmetic: $148.2 \pm 18.8 ; \quad \mathrm{R} 2: \quad 137.7 \pm 18.0$; $F[3,39]=25.930 ; P<0.0001), \mathrm{DBP}(\mathrm{mm} \mathrm{Hg} ; \mathrm{R} 1: 83.1 \pm$ 11.5; manometer: $90.1 \pm 13.3$; mental arithmetic: $91.8 \pm$ 13.2; R2: $86.1 \pm 14.4 ; F[3,39]=26.459 ; P<0.0001), \mathrm{HR}$ (beats/min; R1: $70.7 \pm 8.9$; manometer: $73.2 \pm 11.5$; mental arithmetic: $76.1 \pm 12.1 ; \mathrm{R} 2: 69.8 \pm 9.7 ; F[3,39]=21.296$; $P<0.0001$ ), and HRV (RMSSD in ms; R1: $37.9 \pm 16.7$; manometer: $31.1 \pm 14.2$; mental arithmetic: $32.5 \pm 14.8$; R2: $40.0 \pm 22.7 ; F[3,39]=13.313 ; P<0.0001)$. Whereas blood pressure and HR significantly increased under the stress HRV decreased.

\section{Comparison of high versus low HRV subjects}

Table 1 presents the means and standard deviations of each dependent variable (SBP, DBP, HR, HRV) by HRV group.
High versus low HRV groups did not significantly differ in SBP, DBP, or HR at individual time points (all $P>0.05$ ). However, there was a significant time $\times$ group interaction for $\operatorname{DBP}(F[3,39]=4.0 ; P=0.014)$, referring to a higher and ongoing DBP increase under the stress combined with a lack of post-stress recovery in the low HRV subjects (see Fig. 1).

\section{Heart rate variability}

There was a significant group effect for HRV $(F[1,41]=33.122 ; P<0.0001)$, referring to higher overall HRV levels in the high HRV subjects which accords with the grouping by median split upon baseline HRV. Further, there was a significant time $\times$ group interaction $(F[3,39]=5.650 ; P=0.003)$. Whereas HRV significantly decreased under the stress in the high HRV subjects (from R1 to manometer test; $t(19)=3.565 ; P=0.002$; $r_{\mathrm{pb}}=0.63$ ) and increased with recovery (from mental arithmetic to R2; $t(19)=-3.024 ; P=0.007 ; r_{\mathrm{pb}}=0.57$ ), the low HRV group showed no significant changes in HRV across the four phases of the experiment (see Fig. 2).

\section{Biochemical data}

Table 2 presents the means and standard deviations of each dependent variable (cortisol, TNF-alpha, IL-6) by HRV group.

\section{Cortisol}

There was a significant time effect for cortisol $(F[3,39]=26.512 ; \quad P<0.0001)$, referring to a stressassociated rise $\left(t(41)=-1.874 ; P=0.068, r_{\mathrm{pb}}=0.28\right)$

Table 1 Cardiovascular measures (SBP and DBP in mm Hg, HR in beats per min, and HRV (RMSSD in ms)) during the combined mental stress task for low $(n=23)$ versus high $(n=20)$ HRV subjects

\begin{tabular}{|c|c|c|c|c|c|c|c|}
\hline & $\begin{array}{l}\text { Before } \\
\text { stress (R1) }\end{array}$ & $\begin{array}{l}\text { Manometer } \\
\text { test }\end{array}$ & $\begin{array}{l}\text { Mental } \\
\text { arithmetic }\end{array}$ & $\begin{array}{l}\text { After } \\
\text { stress (R2) }\end{array}$ & $\begin{array}{l}\text { Time } \\
\text { effect }\end{array}$ & $\begin{array}{l}\text { Group } \\
\text { effect }\end{array}$ & Time $\times$ group \\
\hline \multicolumn{8}{|l|}{ SBP } \\
\hline Low HRV & $136.2 \pm 17.1$ & $147.6 \pm 21.8$ & $149.8 \pm 20.4$ & $139.1 \pm 20.9$ & $* * *$ & & \\
\hline High HRV & $132.5 \pm 16.7$ & $145.4 \pm 18.5$ & $145.8 \pm 17.3$ & $135.7 \pm 14.7$ & & & \\
\hline \multicolumn{8}{|l|}{ DBP } \\
\hline Low HRV & $84.6 \pm 11.8$ & $90.3 \pm 14.1$ & $93.5 \pm 14.8$ & $88.9 \pm 17.6$ & $* * *$ & & $*$ \\
\hline High HRV & $80.9 \pm 11.2$ & $89.5 \pm 12.8$ & $89.4 \pm 11.3$ & $82.6 \pm 9.3$ & & & \\
\hline \multicolumn{8}{|l|}{ HR } \\
\hline Low HRV & $72.7 \pm 8.9$ & $74.2 \pm 11.1$ & $77.3 \pm 12.1$ & $72.0 \pm 9.3$ & $* * *$ & & \\
\hline High HRV & $69.0 \pm 8.6$ & $72.4 \pm 12.2$ & $75.4 \pm 12.4$ & $67.7 \pm 9.8$ & & & \\
\hline \multicolumn{8}{|l|}{ RMSSD } \\
\hline Low HRV & $25.8 \pm 6.5$ & $23.5 \pm 6.5$ & $26.1 \pm 8.7$ & $27.2 \pm 8.1$ & $* * *$ & $* * *$ & $* *$ \\
\hline High HRV & $51.7 \pm 13.9$ & $40.0 \pm 15.6$ & $39.9 \pm 17.0$ & $52.5 \pm 26.4$ & & & \\
\hline
\end{tabular}

Shown are means \pm SD of 5 -min phases as analysed by repeated measures ANOVA

$S B P$ systolic blood pressure, $D B P$ diastolic blood pressure, $H R$ heart rate, $H R V$ heart rate variability

$* P<0.05, * * P<0.01, * * * P<0.001$ 


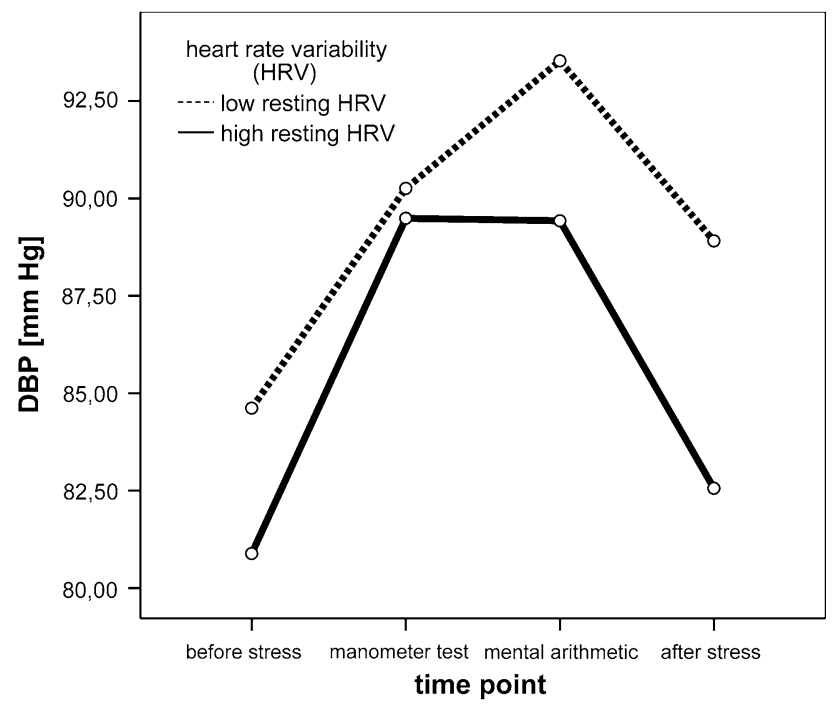

Fig. 1 DBP in subjects with high $(n=20)$ versus low HRV $(n=23)$ during the combined stress task. Shown are means of 5-min phases (R1 before stress, manometer test, mental arithmetic, R2 after stress). The low HRV subjects show a higher and ongoing DBP increase under the stress combined with a lack of post-stress recovery $($ time $\times$ group effect; $F[3,39]=4.004 ; P=0.014)$

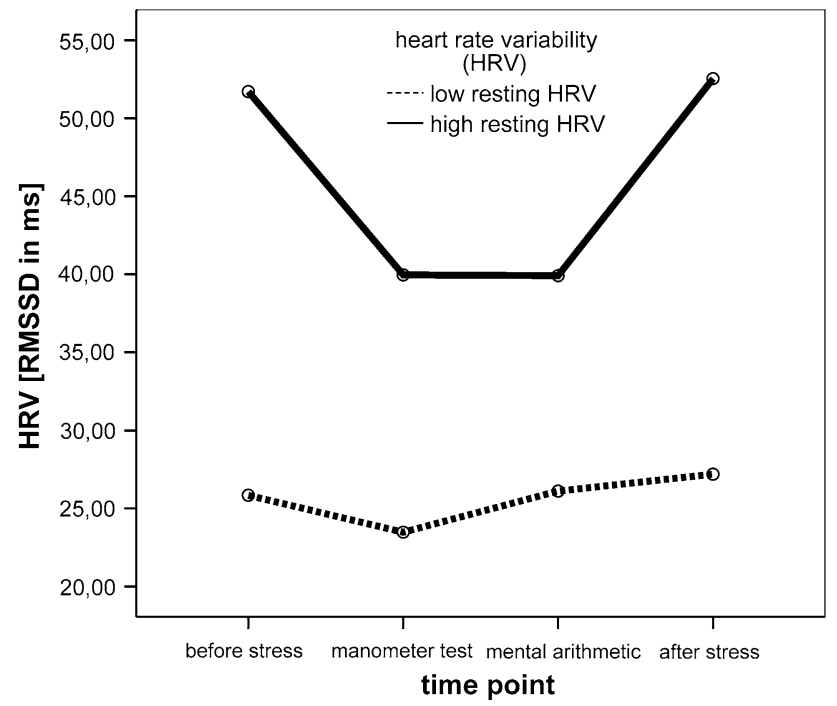

Fig. 2 HRV (RMSSD) in high $(n=20)$ versus low HRV $(n=23)$ subjects during the combined stress task. Shown are means of 5-min phases (R1 before stress, manometer test, mental arithmetic, R2 after stress). The high HRV subjects show higher overall HRV levels $(F[1,41]=33.122 ; P<0.0001)$ and a significant stress-associated modulation of HRV in contrast to the low HRV subjects (time $\times$ group effect; $F[3,39]=5.650 ; P=0.003$ )

and a significant post-stress decrease regarding the whole sample $\left(t(41)=3.713 ; P=0.001, r_{\mathrm{pb}}=0.50\right.$ for cortisol after stress to cortisol at $20 \mathrm{~min}$ post-stress; $t(41)=8.392$; $P<0.0001, r_{\mathrm{pb}}=0.79$ for cortisol at 20 min post-stress to cortisol at $60 \mathrm{~min}$ post-stress). However, looking at the two groups separately, only the high HRV subjects showed significant recovery from stress to $20 \mathrm{~min}$ after stress $\left(t(18)=4.628 ; P<0.0001, r_{\mathrm{pb}}=0.74\right)$, whereas the low HRV group failed to recover at this time point $(P>0.05)$ (see Fig. 3).

\section{Cytokines}

We saw a significant time effect for TNF-alpha $(F[3,32]=3.265 ; P=0.034)$, referring to a significant post-stress decrease of TNF-alpha in the high HRV group $\left(t(17)=2.584 ; P=0.019, r_{\mathrm{pb}}=0.53\right.$ for the post-stress versus the $60 \mathrm{~min}$ post-stress levels), whereas in the low HRV group levels stayed unchanged $(P>0.05$ for the post-stress to the $20 \mathrm{~min}$ and for the post-stress to the 60 min post-stress levels) (see Fig. 4).

For IL-6 there were no significant time, interaction, or group effects at all.

\section{Covariance analyses including age}

There were no significant group main effects for age, nor any significant interaction effects (time $\times$ age) in any of the cardiovascular (SBP, DBP, HR), endocrine (cortisol), or immune measures (TNF-alpha, IL-6) (multivariate analyses; all $P>0.05)$.

\section{Discussion}

The present study investigated acute stress and recovery effects during a combined mental stress test in healthy men. The stress test produced significant cardiovascular responses, as in previous work (Buchholz et al. 2003; Weber et al. 2008). Further, there were significant time effects for cortisol and TNF-alpha, backing the effectiveness of the task in eliciting psychosocial stress (Dickerson and Kemeny 2004). In accordance with our hypothesis, significant differences were observed between subjects with high versus low resting HRV in cardiovascular, endocrine, and immune markers.

\section{Diastolic blood pressure}

Subjects with low baseline HRV showed an ongoing and more pronounced DBP rise under the stress and, more importantly, failed to recover during the following 5-min resting phase, as indicated by a significant time $\times$ group interaction. Previous research suggests that the observed differences between high and low HRV groups may have implications for the future development of cardiovascular disease. In the ARIC study, hypertensives showed significantly reduced HRV in cross-sectional analyses, as well as 
Table 2 Cortisol (nmol/l), TNF-alpha and IL-6 levels (pg/ml) during the combined mental stress task and recovery for low versus high HRV subjects ( $n=22$ vs. $n=19$ for cortisol; $n=18$ vs. $n=18$ for TNF-alpha and IL-6, respectively)

\begin{tabular}{|c|c|c|c|c|c|c|c|}
\hline & $\begin{array}{l}\text { Before stress } \\
\text { (baseline) }\end{array}$ & $\begin{array}{l}\text { Immediately } \\
\text { after stress }\end{array}$ & $\begin{array}{l}20 \mathrm{~min} \\
\text { after stress }\end{array}$ & $\begin{array}{l}60 \mathrm{~min} \\
\text { after stress }\end{array}$ & $\begin{array}{l}\text { Time } \\
\text { effect }\end{array}$ & $\begin{array}{l}\text { Stress versus } \\
20 \text { min post stress }\end{array}$ & $\begin{array}{l}\text { Stress versus } \\
60 \text { min post stress }\end{array}$ \\
\hline \multicolumn{8}{|l|}{ Cortisol } \\
\hline Low HRV & $358.7 \pm 139.5$ & $397.3 \pm 140.7$ & $378.5 \pm 116.4$ & $289.4 \pm 91.5$ & $* * *$ & & \\
\hline High HRV & $357.3 \pm 77.1$ & $388.2 \pm 105.1$ & $341.9 \pm 113.7$ & $284.0 \pm 106.1$ & & $* * *$ & \\
\hline \multicolumn{8}{|l|}{ TNF-alpha } \\
\hline Low HRV & $0.37 \pm .12$ & $0.36 \pm 0.12$ & $0.36 \pm 0.12$ & $0.36 \pm 0.13$ & $*$ & & \\
\hline High HRV & $0.36 \pm 0.14$ & $0.36 \pm 0.12$ & $0.35 \pm 0.11$ & $0.34 \pm 0.12$ & & & $*$ \\
\hline \multicolumn{8}{|l|}{ IL-6 } \\
\hline Low HRV & $4.41 \pm 6.32$ & $4.25 \pm 6.26$ & $4.30 \pm 6.12$ & $4.56 \pm 6.30$ & & & \\
\hline High HRV & $5.87 \pm 10.39$ & $5.75 \pm 10.27$ & $5.27 \pm 8.71$ & $5.14 \pm 8.26$ & & & \\
\hline
\end{tabular}

Shown are means \pm SD of 5-min phases, results of repeated measures ANOVA, and $t$ tests to check for recovery effects in high and low groups separately

$* P<0.05, * * P<0.01, * * * P<0.001$

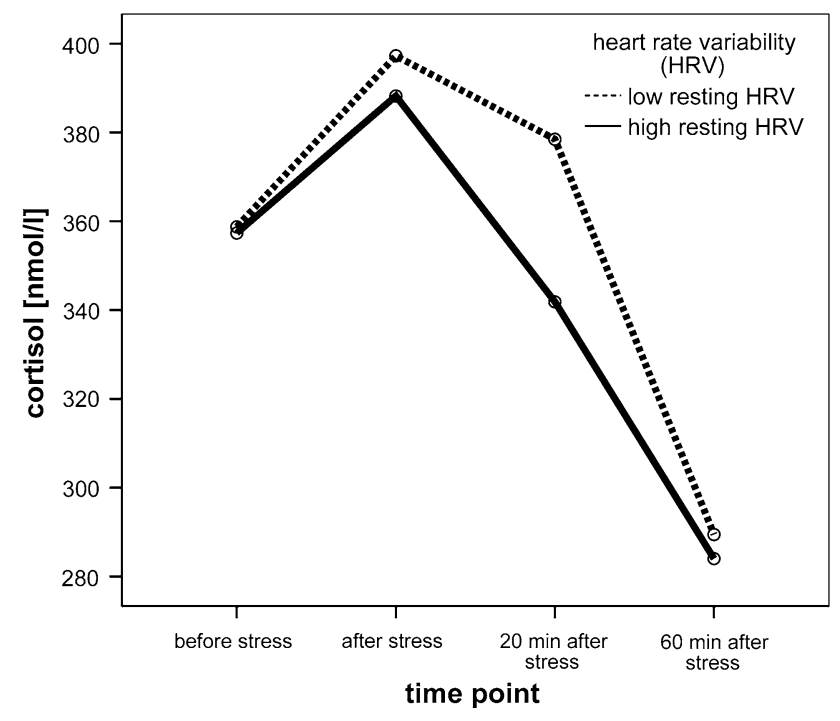

Fig. 3 Cortisol levels in high $(n=19)$ versus low HRV $(n=22)$ groups during the combined stress task (before, after, 20 and $60 \mathrm{~min}$ after stress). Only the high HRV subjects show an immediate poststress recovery $(t(18)=4.628 ; P<0.0001$ for the decrease from stress to $20 \mathrm{~min}$ post stress)

reduced HRV predicting development of hypertension at follow-up after 3 years (Liao et al. 1996). In subjects with no history of cardiovascular disease exposed to acute psychosocial stress, 3-year increases in SBP were predicted by impaired post-stress recovery of SBP, DBP, and total peripheral resistance, and 3-year increases in DBP were predicted by impaired recovery of SBP, DBP, and HRV during tasks, independently of covariates (Steptoe and Marmot 2005). Hence, impaired post-stress recovery as well as reduced baseline HRV may index disturbances in the regulation of cardiovascular stress responses that contribute to longitudinal changes in blood pressure.

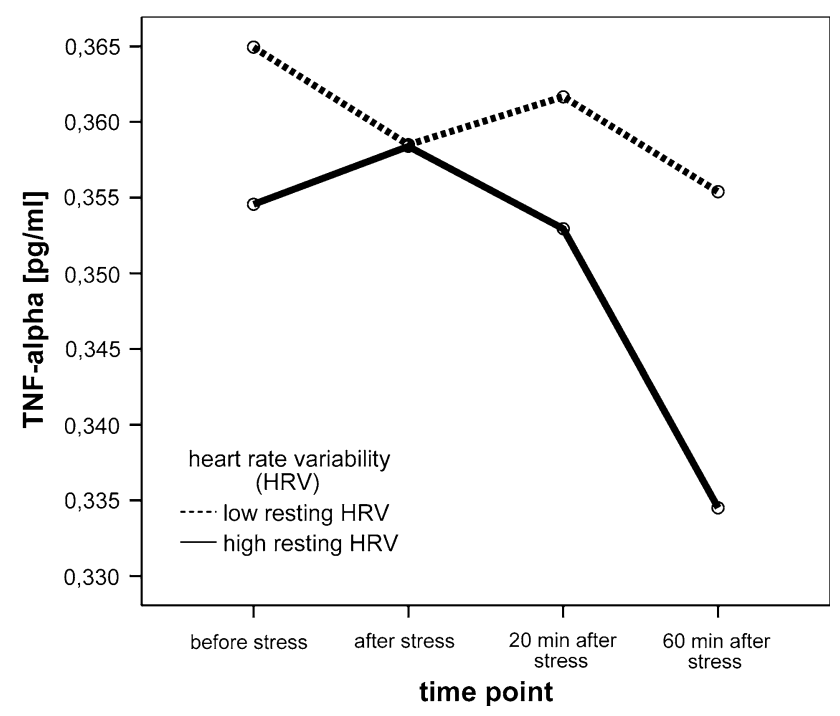

Fig. 4 TNF-alpha levels in high $(n=18)$ versus low HRV $(n=18)$ groups during the combined stress task (before, after, 20 and $60 \mathrm{~min}$ after stress). Only the high HRV subjects show a significant poststress recovery $(t(17)=2.584 ; P=0.019$ for the post-stress versus the $60 \mathrm{~min}$ post-stress levels)

\section{Heart rate variability}

The high HRV individuals showed the expected stressassociated decrease of HRV during the stress tasks and return to baseline levels during recovery (Weber et al. 2008). In contrast, the low HRV subjects stayed at significantly lower HRV levels, unaffected by the stage of the task, with no post-stress recovery. Decreased vagal function as indexed by reduced HRV is associated with the known risk factors for cardiovascular disease and all-cause mortality (Thayer and Lane 2007). Our data further suggest that subjects with low resting HRV do not show contextappropriate responses to environmental challenges. This 
may predispose them to sustained perturbations of sympathovagal balance with subsequent development of cardiovascular disease. Importantly, autonomic imbalance implying decreased vagal tone, and a failure in the adaptation to stressors, such as seen here, may precede the development of manifest disease and hence identify apparently healthy subjects at risk (Thayer et al. 2009), as it has been shown for diabetes mellitus where decreased HRV preceded its manifestation by standard clinical tests (Ziegler et al. 2001).

\section{Cortisol}

Regarding cortisol, all subjects showed almost identical levels before and $60 \mathrm{~min}$ after the stress as well as the height of the stress-associated peak did not significantly differ. However, significant differences were observed at 20 min after stress. Whereas cortisol decreased below baseline in the high HRV group, the low HRV subjects maintained their cortisol at nearly the stress level. This may suggest a heightened stress susceptibility of the HPA axis in the low HRV individuals. Excess cortisol leads to sodium retention, hypokalemia, and elevated blood pressure. Corticosteroids enhance vascular contractility by their permissive effects in potentiating vasoactive responses to catecholamines (Yang and Zhang 2004). Thus, the prolonged activation of the HPA axis in the low HRV subjects in response to a brief psychological challenge may promote hypertension in the long run. Furthermore, impaired recovery is regarded as an index of allostatic load (McEwen 1998). Together with the differences observed between groups in the cardiovascular measures, the data support a common pathway for the regulation of allostatic systems (Thayer et al. 2006; Thayer and Sternberg 2006). The prefrontal cortex and the amygdala are important central nervous system structures linked to the regulation of allostatic systems via the vagus nerve. A lack of inhibitory input by the vagus is thought to lead to perturbations in HPA axis regulation, which may reflect as an impaired recovery response to stress, as observed here in the low HRV group.

\section{Cytokines}

There was no immediate stress-associated change in TNFalpha levels which is concordant with the literature (Altemus et al. 2001; Dugué et al. 1993; Heesen et al. 2002; Miller et al. 2005; Steptoe et al. 2001, 2007). However, our high HRV subjects showed a significant recovery of TNFalpha at $60 \mathrm{~min}$ after stress, with levels falling below baseline, whereas the low HRV group did not show any significant changes. The observed post-stress decrease contrasts with some authors reporting delayed increases of
TNF-alpha, that is, at 45 min post-stress (Altemus et al. 2001; Ellins et al. 2008). Heightened TNF-alpha levels and reduced resting HRV have both been associated with atherogenesis and development of cardiovascular disease (Ridker et al. 2000a). Post-stress recovery may buffer sustained elevations of blood pressure, HR, and other markers of allostatic load (Brosschot et al. 2005; McEwen 1998; Thayer and Sternberg 2006). If this protective mechanism fails under the effect of acute psychosocial stress, such as suggested in our low HRV subjects, an individual may be at increased risk of developing vascular pathology (Kop 2003). Research from animal studies suggests that activation of the efferent vagal pathway plays a role in the tonic inhibitory control of the release of proinflammatory mediators, particularly TNF-alpha (Bernik et al. 2002; Borovikova et al. 2000; Wang et al. 2003). Our results go along with these reports and add to the still scarce body of literature in humans (Janszky et al. 2004; Marsland et al. 2007). Vagal regulation of immune reactivity has been proposed as a pathway linking psychosocial factors to risk for inflammatory processes including atherosclerosis (Marsland et al. 2007; Tracey 2002), which we may on the basis of the present data extend to the postulate of a neurovisceral integration model implying other physiological systems as well (Thayer and Sternberg 2006).

Regarding IL-6, there were no significant changes at all which parallels a number of other (Kop et al. 2008; Miller et al. 2005; Dugué et al. 1993; Lutgendorf et al. 2004; Heinz et al. 2003; Heesen et al. 2002) but not all authors (Edwards et al. 2006; von Känel et al. 2006; Brydon et al. 2005; Steptoe et al. 2001).

Clearly, findings need to be interpreted with caution. Circulating cytokine levels are generally low in healthy subjects, which may hinder the detection of changes (Kop et al. 2008; Steptoe et al. 2007). In addition, we measured unstimulated cytokine levels which are naturally lower than stimulated levels, but have the advantage of reflecting undistorted data. We previously reported a decrease of unstimulated TNF-alpha along with reductions of tinnitus disturbance and perception of stress in a sample of chronic tinnitus sufferers as a result of a 10-week stress management intervention and hence postulating TNF-alpha to be a stress marker (Weber et al. 2002).

Regarding the cardiovascular data, differences between high and low HRV subjects were numerically small, too, as to expect in this healthy male population. At the same time, the Finapres device is known to overestimate absolute blood pressure values (Imholz et al. 1993); however, having excluded hypertensive subjects, we were not so much interested in the absolute values as in the differences between different phases. As raised, our study sample was restricted with respect to gender and ethnicity, as well as the small sample size warrants caution when generalising 
the results to a wider context. However, the fact that significant differences were detected in this small homogenous sample increases the trustworthiness of the results.

To conclude, marked differences in several biological systems occurred between high versus low HRV subjects during recovery from brief mental stress. Whereas the high HRV group showed significant recovery of DBP, HRV, cortisol, and TNF-alpha, the low HRV subjects showed impaired recovery in all of these measures. Whereas the link of autonomic activity and cardiovascular measures may appear evident, the heart being under tonic inhibitory control by the vagus, our results also lend support to a link with the HPA axis (Thayer et al. 2006), as well as supporting the concept of the "cholinergic antiinflammatory pathway" in humans (Tracey 2002). Thus, the data support the inhibitory role that the vagus is thought to play in a neurovisceral regulation model of allostatic systems (Thayer and Sternberg 2006). Common parallel pathways of different biological axes have been delineated earlier (Elenkov and Chrousos 2006). However, our data underline the importance of individual differences in resting HRV in healthy men and provide support for the sensitivity of HRV in detecting a dysregulation of allostatic systems (Thayer and Sternberg 2006; Tracey 2002). We, hence, posit that low resting HRV may identify healthy subjects at risk for future disease, be it cardiovascular (in the first place), (auto-) immune or other stress-related condition. Follow-up studies should verify this hypothesis.

Acknowledgments The authors would like to thank the healthy volunteers for participating in the study and Baerbel Girresch for her help with the biochemical analyses. The study was supported by the Universitäre Forschungsförderung of the Charité (Charité University funding, project no. 2006-874).

Conflict of interest statement There are no financial or other relationships that would lead to a conflict of interest.

\section{References}

Akselrod S, Gordon D, Ubel FA, Shannon DC, Berger AC, Cohen RJ (1981) Power spectrum analysis of heart rate fluctuation: a quantitative probe of beat-to-beat cardiovascular control. Science 213:220-222

al'Absi M, Arnett DK (2000) Adrenocortical responses to psychological stress and risk for hypertension. Biomed Pharmacother 54:234-244

al'Absi M, Lovallo WR, McKey BS, Pincomb GA (1994) Borderline hypertensives produce exaggerated adrenocortical responses to mental stress. Psychosom Med 56:245-250

Altemus M, Rao B, Dhabhar FS, Ding W, Granstein RD (2001) Stress-induced changes in skin barrier function in healthy women. J Invest Dermatol 117(2):309-317

Bernik TR, Friedman SG, Ochani M, DiRaimo R, Ulloa L, Yang H, Sudan S, Czura CJ, Ivanova SM, Tracey KJ (2002)
Pharmacological stimulation of the cholinergic antiinflammatory pathway. J Exp Med 195(6):781-788

Borovikova LV, Ivanova S, Zhang M, Yang H, Botchkina GI, Watkins LR, Wang H, Abumrad N, Eaton JW, Tracey KJ (2000) Vagus nerve stimulation attenuates the systemic inflammatory response to endotoxin. Nature 405(6785):458-462

Brook RD, Julius S (2003) Autonomic imbalance, hypertension, and cardiovascular risk. Am J Hypertens $13(6 \mathrm{Pt} 2): 112 \mathrm{~S}-122 \mathrm{~S}$

Brosschot JF, Pieper S, Thayer JF (2005) Expanding stress theory: prolonged activation and perseverative cognition. Psychoneuroendocrinology 30(10):1043-1049

Brydon L, Edwards S, Jia H, Mohamed-Ali V, Zachary I, Martin JF, Steptoe A (2005) Psychological stress activates interleukin-1beta gene expression in human mononuclear cells. Brain Behav Immun 19(6):540-546

Buchholz K, Schachinger H, Wagner M, Sharma AM, Deter HC (2003) Reduced vagal activity in salt-sensitive subjects during mental challenge. Am J Hypertens 16:531-536

Deter HC, Buchholz K, Schorr U, Mathiak K, Sharma AM (2001) Salt-sensitivity and other predictors of stress-related cardiovascular reactivity in healthy young males. Clin Exp Hypertens 23:213-225

Dickerson SS, Kemeny ME (2004) Acute stressors and cortisol responses: a theoretical integration and synthesis of laboratory research. Psychol Bull 130(3):355-391

Dugué B, Leppänen EA, Teppo AM, Fyhrquist F, Gräsbeck R (1993) Effects of psychological stress on plasma interleukins-1 beta and 6 , C-reactive protein, tumour necrosis factor alpha, anti-diuretic hormone and serum cortisol. Scand J Clin Lab Invest 53(6):555-561

Edwards KM, Burns VE, Ring C, Carroll D (2006) Sex differences in the interleukin- 6 response to acute psychological stress. Biol Psychol 71(3):236-239

Elenkov IJ, Chrousos GP (2006) Stress system-organization, physiology and immunoregulation. Neuroimmunomodulation 13(5-6):257-267

Ellins E, Halcox J, Donald A, Field B, Brydon L, Deanfield J, Steptoe A (2008) Arterial stiffness and inflammatory response to psychophysiological stress. Brain Behav Immun Mar 1 [Epub ahead of print]

Fliege H, Rose M, Arck P, Walter OB, Kocalevent RD, Weber CS, Klapp BF (2005) The Perceived Stress Questionnaire (PSQ) reconsidered: validation and reference values from different clinical and healthy adult samples. Psychosom Med 67:78-88

Heesen C, Schulz H, Schmidt M, Gold S, Tessmer W, Schulz KH (2002) Endocrine and cytokine responses to acute psychological stress in multiple sclerosis. Brain Behav Immun 16(3):282-287

Heinz A, Hermann D, Smolka MN, Rieks M, Gräf KJ, Pöhlau D, Kuhn W, Bauer M (2003) Effects of acute psychological stress on adhesion molecules, interleukins and sex hormones: implications for coronary heart disease. Psychopharmacology (Berl) 165(2):111-117

Huikuri HV, Jokinen V, Syvänne M, Nieminen MS, Airaksinen KE, Ikäheimo MJ, Koistinen JM, Kauma H, Kesäniemi AY, Majahalme S, Niemelä KO, Frick MH (1999) Heart rate variability and progression of coronary atherosclerosis. Arterioscler Thromb Vasc Biol 19(8):1979-1985

Imholz BP, Langewouters GJ, van Montfrans GA, Parati G, van Goudoever J, Wesseling KH, Wieling W, Mancia G (1993) Feasibility of ambulatory, continuous $24 \mathrm{~h}$ finger arterial pressure recording. Hypertension 21:65-73

Janszky I, Ericson M, Lekander M, Blom M, Buhlin K, Georgiades A, Ahnve S (2004) Inflammatory markers and heart rate variability in women with coronary heart disease. J Intern Med 256:421-428

Kop WJ (2003) The integration of cardiovascular behavioral medicine and psychoneuroimmunology: new developments based on converging research fields. Brain Behav Immun 17(4):233-237 
Kop WJ, Weissman NJ, Zhu J, Bonsall RW, Doyle M, Stretch MR, Glaes SB, Krantz DS, Gottdiener JS, Tracy RP (2008) Effects of acute mental stress and exercise on inflammatory markers in patients with coronary artery disease and healthy controls. Am J Cardiol 101(6):767-773

Kraemer HC, Stice E, Kazdin A, Offord D, Kupfer D (2001) How do risk factors work together? Mediators, moderators, and independent, overlapping, and proxy risk factors. Am J Psychiatry 158(6):848-856

Laux L, Glanzmann P, Schaffner P, Spielberger CD (1981) STAI State-Trait-Angstinventar. Beltz, Weinheim

Levenstein S, Prantera C, Varvo V, Scribano ML, Berto E, Luzi C, Andreoli A (1993) Development of the Perceived Stress Questionnaire-A new tool for psychosomatic research. J Psychosom Res 37:19-32

Liao D, Cai J, Barnes RW, Tyroler HA, Rautaharju P, Holme I et al (1996) Association of cardiac autonomic function and the development of hypertension: the ARIC study. Am J Hypertens 9:1147-1156

Lutgendorf SK, Logan H, Costanzo E, Lubaroff D (2004) Effects of acute stress, relaxation, and a neurogenic inflammatory stimulus on interleukin-6 in humans. Brain Behav Immun 18(1):55-64

Marsland AL, Gianaros PJ, Prather AA, Jennings JR, Neumann SA, Manuck SB (2007) Stimulated production of proinflammatory cytokines covaries inversely with heart rate variability. Psychosom Med 69(8):709-716

McEwen BS (1998) Stress, adaptation, and disease Allostasis and allostatic load. Ann N Y Acad Sci 840:33-44

Melzig CA, Weike AI, Hamm AO, Thayer JF (2009) Individual differences in fear-potentiated startle as a function of resting heart rate variability: implications for panic disorder. Int $\mathrm{J}$ Psychophysiol 71(2):109-117

Miller GE, Rohleder N, Stetler C, Kirschbaum C (2005) Clinical depression and regulation of the inflammatory response during acute stress. Psychosom Med 67(5):679-687

Packard RR, Libby P (2008) Inflammation in atherosclerosis: from vascular biology to biomarker discovery and risk prediction. Clin Chem 54(1):24-38

Ridker PM, Rifai N, Pfeffer M, Sacks F, Lepage S, Braunwald E (2000a) Elevation of tumor necrosis factor-alpha and increased risk of recurrent coronary events after myocardial infarction. Circulation 101(18):2149-2153

Ridker PM, Rifai N, Stampfer MJ, Hennekens CH (2000b) Plasma concentration of interleukin- 6 and the risk of future myocardial infarction among apparently healthy men. Circulation 101(15): $1767-1772$

Ross R (1999) Atherosclerosis is an inflammatory disease. Am Heart J 138(5 Pt 2):S419-S420

Schwenkmezger P, Hodapp V (1991) The state-trait anger expression inventory. Zeitschrift Fur Klinische Psychologie Psychiatrie und Psychotherapie 39:63-68

Sloan RP, McCreath H, Tracey KJ, Sidney S, Liu K, Seeman T (2007) RR interval variability is inversely related to inflammatory markers: the CARDIA study. Mol Med 13(3-4):178-184

Spielberger CD (1983) Manual for the state-trait anxiety inventory. Consulting Psychologist Press, Palo Alto, CA

Spielberger CD (1999) Manual for the state-trait anger inventory, STAXI-2. Psychological Assessment Resources, Odessa, FL

Steptoe A, Marmot M (2005) Impaired cardiovascular recovery following stress predicts 3-year increases in blood pressure. J Hypertens 23(3):529-536

Steptoe A, Marmot M (2006) Psychosocial, hemostatic, and inflammatory correlates of delayed poststress blood pressure recovery. Psychosom Med 68(4):531-537
Steptoe A, Willemsen G, Owen N, Flower L, Mohamed-Ali V (2001) Acute mental stress elicits delayed increases in circulating inflammatory cytokine levels. Clin Sci (Lond) 101(2):185-192

Steptoe A, Hamer M, Chida Y (2007) The effects of acute psychological stress on circulating inflammatory factors in humans: A review and meta-analysis. Brain Behav Immun 21(7):901-912

Task Force of the European Society of Cardiology and the North American Society of Pacing and Electrophysiology (1996) Heart rate variability. Standards of measurement, physiological interpretation, and clinical use. Task Force of the European Society of Cardiology and the North American Society of Pacing and Electrophysiology. Eur Heart J 17:354-381

Thayer JF (2006) On the importance of inhibition: central and peripheral manifestations of nonlinear inhibitory processes in neural systems. Dose Response 4:2-21

Thayer JF, Brosschot JF (2005) Psychosomatics and psychopathology: looking up and down from the brain. Psychoneuroendocrinology 30:1050-1058

Thayer JF, Fischer JE (2009) Heart rate variability, overnight urinary norepinephrine, and C-reactive protein: evidence for the cholinergic anti-inflammatory pathway in healthy human adults. J Intern Med 265:439-447

Thayer JF, Lane RD (2007) The role of vagal function in the risk for cardiovascular disease and mortality. Biol Psychol 74:224-242

Thayer JF, Lane RD (2009) Claude Bernard and the heart-brain connection: further elaboration of a model of neurovisceral integration. Neurosci Biobehav Rev 33:81-88

Thayer JF, Sternberg E (2006) Beyond heart rate variability: vagal regulation of allostatic systems. Ann N Y Acad Sci 1088:361372

Thayer JF, Hall M, Sollers JJ, Fischer JE (2006) Alcohol use, urinary cortisol, and heart rate variability in apparently healthy men: evidence for impaired inhibitory control of the HPA axis in heavy drinkers. Int J Psychophysiol 59:244-250

Thayer JF, Yamamoto SS, Brosschot JF (2009) The relationship of autonomic imbalance, heart rate variability and cardiovascular disease risk factors. Int J Cardiol. doi:10.1016/j.icard.2009. 09.543

Tracey KJ (2002) The inflammatory reflex. Nature 420:853-859

Tsuji H, Larson MG, Venditti FJ Jr, Manders ES, Evans JC, Feldman CL, Levy D (1996) Impact of reduced heart rate variability on risk for cardiac events. The Framingham Heart Study. Circulation 94(11):2850-2855

Vasey MW, Thayer JF (1987) The continuing problem of false positives in repeated measures ANOVA in psychophysiology: a multivariate solution. Psychophysiololgy 24:479-486

von Känel R, Kudielka BM, Preckel D, Hanebuth D, Fischer JE (2006) Delayed response and lack of habituation in plasma interleukin- 6 to acute mental stress in men. Brain Behav Immun 20(1):40-48

Walker BR, Phillips DI, Noon JP, Panarelli M, Andrew R, Edwards HV, Holton DW, Skl JR, Webb DJ, Watt GC (1998) Increased glucocorticoid activity in men with cardiovascular risk factors. Hypertension 31(4):891-895

Wang H, Yu M, Ochani M, Amella CA, Tanovic M, Susarla S, Li JH, Wang H, Yang H, Ulloa L, Al-Abed Y, Czura CJ, Tracey KJ (2003) Nicotinic acetylcholine receptor alpha7 subunit is an essential regulator of inflammation. Nature 421(6921):384 388

Watt GC, Harrap SB, Foy CJ, Holton DW, Edwards HV, Davidson HR, Connor JM, Lever AF, Fraser R (1992) Abnormalities of glucocorticoid metabolism and the renin-angiotensin system: a four-corners approach to the identification of genetic determinants of blood pressure. J Hypertens 10(5):473-482 
Weber C, Arck P, Mazurek B, Klapp BF (2002) Impact of a relaxation training on psychometric and immunologic parameters in tinnitus sufferers. J Psychosom Res 52(1):29-33

Weber CS, Thayer JF, Rudat M, Perschel HF, Buchholz K, Deter HC (2007) Emotional irritation before mental stress is associated with enhanced peripheral norepinephrine. Scand J Psychol 48(6):459-466

Weber CS, Thayer JF, Rudat M, Sharma AM, Perschel FH, Buchholz K, Deter HC (2008) Salt sensitive males show reduced heart rate variability, lower norepinpehrine and enhanced cortisol during mental stress. J Hum Hypertens 22(6):423-431
Yang S, Zhang L (2004) Glucocorticoids and vascular reactivity. Curr Vasc Pharmacol 2(1):1-12

Ziegler D, Laude D, Akila F, Elghozi JL (2001) Time and frequency domain estimation of early diabetic cardiovascular autonomic neuropathy. Clin Auton Res 11:369-376

Zimmermann-Viehoff F, Weber CS, Merswolken M, Rudat M, Deter HC (2008) Low anxiety males display higher degree of salt sensitivity, increased autonomic reactivity, and higher defensiveness. Am J Hypertens 21(12):1292-1297 